\title{
Human Toxocarosis. Its Seroprevalence in the City of La Plata
}

\section{NE Radman/ ${ }^{+}$, SM Archelli, RD Fonrouge, M del V Guardis, OR Linzitto}

Cátedra de Parasitología Comparada, Laboratorio de Parasitosis Humanas y Zoonosis Parasitarias, Facultad de Ciencias Veterinarias, UNLP, 60 y 118 (1900) La Plata, Buenos Aires, Argentina

Toxocara canis is very common in dogs throughout the world. It is the primary cause of visceral larva migrans (VLM) in humans. Soil contaminated with T. canis embryonated eggs is the main source of infection of man. Our objective was to describe Toxocara seroprevalence in humans in the city of La Plata associated with some determinants such as age, presence or absence of clinical manifestations and risk factors. Blood samples were collected at random from 156 patients of different sex and age, with and without clinical symptoms compatible with the disease. The diagnostic technique ELISA test was performed with the Bordier Affinity Products Commercial Kit, using excretory-secretory Toxocara antigen with a sensitivity higher than $90 \%$. The values were positive in $39 \%$ of the studied population. In the analysis according to age, the younger group presented significant differences with respect to the older one (Chi-square $p<0.05)$. Positive patients presented clinical symptoms compatible with the disease $(84 \%)$, and $41 \%$ presented some risk factor. The level of positivity obtained indicates a certain risk of being infectes mainly in patients younger than 15 years old. The authors agree that an early identification and treatment of VLM may save a life.

Key words: toxocarosis - seroprevalence - La Plata - Argentina

Some nematode parasites of animals can infect noncompatible hosts such as humans (Agudelo et al. 1990, Bouchard et al. 1994, Buijs et al. 1994, Gueglio et al. 1994) and remain in their organisms as migrating larvae arrested in their development but metabolically active (Pezzani et al. 1993), eliciting mechanical damages that are exacerbated by the host's immune response (Agudelo et al. 1990, Hirata et al. 1990).

Species of Toxocara (parasites of dogs, cats and cattle) and Baylisascaris (very frequent ascarid in procionids), determine visceral larvae migrans (VLM) in paratenic hosts including man (Kazacos \& Boyce 1990, Glickman \& Magnaval 1993,Pezzani et al. 1993, Gueglio et al. 1994, Papini \& Casarosa 1994).

T. canis is very common in dogs throughout the world (Agudelo et al. 1990). It is the primary cause of VLM in humans (Sánchez et al. 1994). Toxocarosis is a systemic larval parasitosis that may affect humans of different age or sex (Beaver 1956, Agudelo et al. 1990, Gueglio et al. 1994). It may appear in the following forms: (i) ocular larva migrans (OLM), always with serious lesions that

\footnotetext{
$\overline{{ }^{+} \text {Corresponding author. Fax: }}+54$-221- 4257980. E-mail: nildarad@ fcv.med vet.unlp.edu.ar

Recevied 9 June 1999

Accepted 18 January 2000
}

can produce leukocoria, uveitis, retinal granulomas or chronic endophthalmitis, very often with a decrease of the visual acuity and strabismus (Beaver 1956, Villano et al. 1992, Kujat et al. 1993, Minvielle et al. 1993, Sharkey \& Mc Kay 1993); (ii) VLM associated with different clinical manifestations: hepatitis (Minvielle et al. 1993), diffuse pulmonary involvement (Hotez 1993), severe asthma (Glickman \& Magnaval 1993), severe eosinophilic pneumonia (Hirata et al. 1990), cutaneous disorders (Kasacos \& Boyce 1990, España et al. 1993), myocardial (Kujat et al. 1993) and gastroenteric affections (Jansen et al. 1993) as well as those of the central nervous system (Beaver 1956, Khalil et al. 1971, Woodruff 1975, Sellal et al. 1992, Glickman \& Magnaval 1993, Stenfancikova et al. 1993, Kumar \& Kimm 1994) usually accompanied by persistent eosinophilic increase ranging from moderate to severe; (iii) covert toxocarosis with nonspecific symptomatology: hepatomegaly, abdominal pain, sleep disturbances, headache (Agudelo et al. 1990) and associated with normal or slightly increased eosinophilia.

Soil contaminated with $T$. canis embryonated eggs is the main source of human infection. Contamination levels are variable in different regions of the world (Martínez et al. 1973, Esterre \& Agis 1985, Venturini \& Radman 1988, Stenfancikova et al. 1993, Bouchard et al. 1994, Papini \& Casarosa 1994). Nevertheless, infection of humans is also possible due to the ingestion of tissues of other 
paratenic hosts like birds, rabbits, pigs and cattle infected with T. canis larvae (Agudelo et al. 1990, Kasacos \& Boyce 1990).

The objective of this study was to describe Toxocara seroprevalence in humans in the city of La Plata, associated with some determinants such as age, presence or absence of clinical manifestations and risk factors.

\section{MATERIALS AND METHODS}

Human sera - Blood samples were taken from 156 patients, seen in outpatient clinics and hospitals in La Plata, of different sexes and ages, with or without clinical symptoms compatible with the disease.

Statistical methodology - Sampling at random, with an estimated proportion of presence of $25 \%$ of the population, an absolute error of $10 \%$ and a significance of $95 \%$. The Chi-square test was used to calculate the association with possible determinants (age, clinical manifestations and risk factors). Measuring of the already pointed determinants through of odds ratio (Odds Ratio $=$ O.R.) (EPIDAT 1994).

Diagnostic methodology - The ELISA test using T. canis excretory and secretory antigen with a reported sensitivity greater than $90 \%$ was performed according to the manufacturer's instructions (Bordier Affinity Products Commercial Kit). The sera were not absorbed with Ag de Ascaris suum (Nunes et al. 1997). Serologic results were grouped according to a simple scale: 0 (negative), 1 (positive), 2 (highly positive), following a similar criterium as Gueglio et al. (1994).

Categories according to age - Individuals were divided into two groups: younger than 15 years old, and older than 16 years old.

Clinical and epidemiological data - An individual record was made and the following data were registered: clinical data: they included anamnestic data, laboratory values, clinical signs and symptoms (pulmonary infiltrates, bronchospasms, hepato- and splenomegaly, strabismus, retinitis, chorioretinitis, leukochoria, glaucoma, decrease of the visual acuity, convulsions and other signs of central nervous system involvement, pruritus and/ or generalized eczema and an increase in eosinophil counts); epidemiological data: risk factors (ownership of dogs and/or cats, a history of pica, professional activities such as veterinarians, dog keepers, kennel men, etc.); eosinophil count: normal eosinophils (0-3\%), mild (4-10\%), moderate (11-15\%) and severe (16->\%) eosinophilia.

\section{RESULTS}

From 156 human sera tested, 61 were positive $(39 \%)$ to the ELISA test.
A transversal study of distribution as regards age and the diagnostic test show a significantly higher proportion of positivity in patients younger than 15 years old (Table I).

Relating ages to diagnostic test values, we can observe a larger number of highly positive ( 2 in our scale) results in the younger patients, although this difference is not statistically significant (Table II).

The association between symptoms and the test shows that the correlation of symptoms to serology is highly significant (Table III).

In Table IV, descriptive data referring to individual clinical signs and symptoms according to age and serologic results are presented.

Eosinophilia levels according to age and the diagnostic test are presented in Table V.

The risk factors evaluated were not associated with the proportion of positivity to the diagnostic test (Table VI) .

TABLE I

Toxocarosis, age distribution

\begin{tabular}{lcc}
\hline Age/diagnos & ELISA (+) & ELISA (-) \\
\hline Younger & 38 & 43 \\
Older & 23 & 52 \\
\hline Total & 61 & 95
\end{tabular}

Chi-square $=4,317 ;$ P-value $=0,0377 ;$ Odds Ratio $=1,99$

TABLE II

Age and diagnostic gradients distribution

\begin{tabular}{lcccr}
\hline Age/gradients & ELISA 0 & ELISA 1 & ELISA 2 & Total \\
\hline Younger & 43 & 13 & 25 & 81 \\
Older & 52 & 7 & 16 & 75 \\
\hline Total & 95 & 20 & 41 & 156 \\
\hline
\end{tabular}

TABLE III

Toxocarosis - Distribution of symptoms as related to serology

\begin{tabular}{lccc}
\hline $\begin{array}{l}\text { Symptoms/ } \\
\text { diagnostic }\end{array}$ & ELISA(+) & ELISA(-) & Total \\
\hline Present & 51 & 41 & 92 \\
Absent & 10 & 54 & 64 \\
\hline Total & 61 & 95 & 156 \\
\hline
\end{tabular}

Chi-square.:=25,119; P-value $=0,0000005$; Odds Ratio $=6,72$ 
TABLE IV

Clinical signs and symptoms, age and diagnostic test results

\begin{tabular}{|c|c|c|c|c|c|}
\hline \multirow[t]{2}{*}{ Signs/symptoms } & \multicolumn{2}{|c|}{$\begin{array}{l}\text { Younger } \\
\text { ELISA }\end{array}$} & \multicolumn{2}{|c|}{$\begin{array}{l}\text { Older } \\
\text { ELISA }\end{array}$} & \multirow[t]{2}{*}{ Total } \\
\hline & $(+)$ & $(-)$ & $(+)$ & $(-)$ & \\
\hline Respiratory & 6 & 0 & 12 & 12 & 30 \\
\hline Neurologica & 3 & 5 & 4 & 1 & 13 \\
\hline Ocular & 2 & 2 & 2 & 3 & 9 \\
\hline Hepatic & 2 & 1 & 1 & 0 & 4 \\
\hline Cutaneous & 0 & 0 & 2 & 0 & 2 \\
\hline Splenomegaly & 1 & 0 & 0 & 0 & 1 \\
\hline Totals & 14 & 8 & 21 & 16 & 59 \\
\hline
\end{tabular}

TABLE V

Eosinophilia levels according to age and diagnostic test

\begin{tabular}{|c|c|c|c|c|c|c|}
\hline \multicolumn{2}{|c|}{ Eosinophilia } & \multicolumn{2}{|c|}{ Younger } & \multicolumn{2}{|c|}{ Older } & \multirow[t]{2}{*}{ Totals } \\
\hline & & $(+)$ & $(-)$ & $(+)$ & $(-)$ & \\
\hline Normal & $0-3 \%$ & 4 & 15 & 5 & 25 & 49 \\
\hline Mild & $4-10 \%$ & 12 & 11 & 10 & 10 & 43 \\
\hline Moderate & $11-15 \%$ & 6 & 4 & 4 & 1 & 15 \\
\hline Severe & $16->\%$ & 8 & 1 & 4 & 0 & 13 \\
\hline Totals & & 30 & 31 & 23 & 36 & 120 \\
\hline
\end{tabular}

TABLE VI

Risk factors and diagnostic distribution

\begin{tabular}{lccr}
\hline Risk factors & ELISA $(+)$ & ELISA $(-)$ & Total \\
\hline Present & 25 & 26 & 51 \\
Absent & 36 & 69 & 105 \\
\hline Total & 61 & 95 & 156
\end{tabular}

Chi square: $=3,13 ; \mathrm{P}$-value $=0,0768$

\section{DISCUSSION}

As Hirata et al. (1990) and Villano et al. (1992) affirm in their investigations, the diagnostic confirmation of toxocarosis should be based on demostrations of larvae in tissue, but this is invasive and not always possible. Therefore, imaging procedures (Hirata et al. 1990, Kumar \& Kimm 1994) are extremely valuable in addition to serological techniques (Hirata et al. 1990, Villano et al. 1992). In this work, using ELISA test as a diagnostic technique, a high percentage of seroprevalence $(39 \%)$ was observed. This value exceeds the percentage found in France by Gueglio et al. (1994) (22\%). In our study the ELISA test was not made after absorption of serun samples with extracts of Ascaris suum, likely is routinely made in Brasil, what might have avoided confusing serodiagnostics, probably reducing the percentage of seropositives (Nunes et al. 1997).
The positivity figures are significantly higher and the risk is twice as high in patients younger than 15 years old than in older patients, as found in the investigations performed by Sanchez et al. (1994). Nevertheless, in Slovakia, Stefacikova et al. (1993) no significant differences are observed in relation to age. Agudelo et al. (1990) indicate an increase of positivity in older age.

Individuals with highly positive diagnostic test results (ELISA 2) were more frequent in the younger group, this could show a tendency to a higher reactivity in this group, or it may be due to more recent infections.

The pathogenesis of toxocarosis is attributed to the mechanical damage produced by larvae when migrate through the viscera and the degree host's inflammatory response. Clinical manifestations are variable and depend on number of infective eggs ingested, Hotez (1993), number of migrating larvae, infection frequency, organ or tissue involved and the allergic response induced in the host. According to Agudelo et al. (1990), Hirata et al. (1990), Kumar and Kimm (1994) and Sanchez et al. (1994), there is a high proportion of seropositive persons that do no present recognizable symptoms for toxocarosis; therefore, the limit between infection and disease is dificult to establish.

Some of the individuals of the group that presented symptoms were seronegative for 
toxocarosis. These symptoms with clinicaly compatibly with the parasitosis may be due to a different etiology.

The group without clinical manifestations and positive serology might be patients with covert toxocarosis, or perhaps, the antibodies detected belonged to a residual infection, since once the larva is dead, the antibodies only disappear after a long period of time. Agudelo et al. (1990) and Kumar and Kimm (1994) say that there is no complete correlation between serologic results and development of clinical disease.

In agreement with Buijs (1994), respiratory symptomatology was the clinical feature most frequently observed in both groups, younger or older patients, and included from slight to very severe manifestations.

Glickman et al. (1985) mentions that the pathology caused by migrating larvae of $T$. canis in the central nervous system covers from slight changes to fatal neurological disease. Woodruff (1975) and Hotez (1993) point out the association between neurological disturbances and toxocarosis. Villano et al. (1992) describe spastic tetraparesis and hypoaesthesia in toxocarosis located in the spinal-cord zone.

In this study, neurological presentations were more frequent than respiratory disease, particularly in older patients. It would be advisable to remark that in other investigations $T$. canis larva located in the brain could possibly act as epileptogenic foci, according to what Sellall et al. (1992) and Kujat et al. (1993) mentioned in their publications.

Sharkey et al. (1993), Glickman et al. (1985) point out that ocular toxocarosis may have a negative ELISA test, probably due to a low concentration of circulating antibodies in this form of presentation of the disease. Nevertheless in our group, in four out of nine individuals suffering ocular lesions compatible with the disease, positive results were obtained. According to Glickman et al. (1985) a single larva in the eye may cause serious damages, therefore, an early diagnosis is very important.

Glickman et al. (1985) and España et al. (1993) mention cutaneous manifestations such as pruritus, rash, urticaria, erythematous subcutaneous nodules, pruritic ulcers, papules and purpura, associated with toxocarosis. In this investigation only two cases of generalized severe eczema were found, all occurring in adults.

Gueglio et al. (1994) and Glickman (1993) associate toxocarosis with high counts of circulating eosinophils, but in this study, 41 seropositive individuals $(77 \%)$ showed normal, light or moderate eosinophilia, and only two patients (23\%) presented high eosinophils counts.

A higher Toxocara seroprevalence is generally associated with risk factors. Buijs et al. (1994) do not find any relation between seropositivity and risk factors. In our study, performed with a test with higher reliability $(90 \%)$, the risk factors considered were associated with higher seropositivity.

Studies on dog faeces and soil performed in other countries as well as in the city of La Plata by other authors (Martínez et al. 1973, Esterre et al. 1985, Venturini et al. 1988, Agudelo et al. 1990, Jansen et al. 1993, Kujat et al. 1993, Minvielle et al. 1993) indicate high percentages of dogs infected with the nematode T. canis and a high contamination of the soil with embryonated forms of the parasite, identifying a certain risk. More complete studies consisting of a routine test and a subsequent control with higher sensitivity techniques, should be done in humans.

As Glickman et al. (1993) say, an early identification and treatment of VLM may save a life.

\section{ACKNOWLEDGMENTS}

To Lucila Maria Venturini, Mabel Iris Spagnolo and Hector Alejandro Riafrecha, for their contributions to this work.

\section{REFERENCES}

Agudelo C, Villarreal E, Caceres E, Lopez C, Eljach J, Ramirez N, Hernandez C, Corredor A 1990. Human and dogs Toxocara canis infection in a poor neighborhood in Bogota. Mem Inst Oswaldo Cruz 85: 75-78.

Beaver PC 1956. Larva migrans. Exp Parasitol 5: 587621.

Bouchard O, Arbib F, Paramelle B, Brambilla C 1994. Pneumopathie eosinophilique aigue et syndrome de larva migrans. A propos dún cas chez un adulte. Rev Mal Resp 11: 593-595.

Buijs J, Borsboom G, Van Gemund JJ, Hazebroek AL, Van Dongen PAM, Van Knapen F, Neijens H 1994. Toxocara seroprevalence in 5-year-old elementary school chidren: relation with allergic asthma. Am J Epidemiol 140: 839-847.

EPIDAT 1994. Análisis epidemiológico de datos tabulados. Versión 1.0. Servicio Galego de Saude OPS, OMS, Galicia, España, 75 pp.

España A, Serna M, Rubio M, Redondo P, Quintanilla E 1993. Secondary urticaria due to toxocariasis: possibly caused by ingesting raw cattle meat? J Invest Allergol Clin Inmunol 3: 51-52.

Esterre P, Agis F 1985. Les nematodes du sable des plages en Guadeloupe: problemes de sante publique associes. Bull Soc Path Ex 78: 71-78.

Glickman L, Grieve R, Lauria S, Jones D 1985. Serodiagnosis of ocular toxocariasis: a comparison of two antigens. J Clin Pathol 38: 103-107.

Glickman LT, Magnaval JF 1993. Zoonotic roundworm infections. Infect Dis Clin North America 7: 717.

Gueglio B, Gentile L, Nguyen JM, Achard J, Chabasse 
D, Marjolet M 1994. Epidemiologic approach to human toxocariasis in western France. Parasitol Res 80: 531-536.

Hirata T, Yamasaki K, Li Yong-guo, Majima Y, Tsuji M 1990. Demostration of hepatic granuloma due to visceral larva migrans by ultasonography. J Clin $\mathrm{Ul}$ trasound 18: 429-433.

Hotez PJ 1993. Visceral and ocular larva migrans. Seminars in Neurol 13: 175-179.

Jansen J, van Knapen F, Schereus M, van Wijngaarden Th 1993. Toxocara eieren in parken en zandbakken in de stad utrecht. Tijdschr Diergeneeskd 118: 4.

Kazacos KR, Boyce WM 1990. Baylisascaris larva migrans. JAVMA 195: 894-903.

Khalil HM, Khattab AK, El-Fattah SMA, Khalid ML, Awaad S, Rifaat MA 1971. Interrelationship between poliomyelitis and Toxocara infection. Tran $R$ Soc Trop Med Hyg 65: 599-601.

Kujat VCh, Ruttinger P, Piepgras U 1993. Zerebrale toxocariasis. Fortschr Rontgenstr 159: 487-488.

Kumar J, Kimm J 1994. MR in Toxocara canis myelopathy. AJNR 15: 1918-1920.

Martinez AH, Led JE, Albariño M 1973. Resultados obtenidos sobre 5.000 análisis coproparasitológicos en perros de la ciudad de La Plata y alrededores. Rev Agr y Vet 2: 2-10.

Minvielle MC, Pezzani BC, Basualdo JA 1993. Frecuency of finding helminths eggs in canine stool samples collected in public places from La Plata city, Argentina. Bol Chileno de Parasit 48: 63-65.

Nunes CM, Tundisi RN, García JF, Heinemann MB,
Ogassawara S, Richtzenhain J 1997. Cross-reactions between Toxocara canis and Ascaris suum in the diagnosis of visceral larva migrans by western blotting technique. Rev Inst Med Trop S Paulo 39: 253-256.

Papini R, Casarosa L 1994. Observations on the infectivity of Baylisascaris transfuga eggs for mice. Vet Parasitol 51: 283-288.

Pezzani BC, Minvielle MC, Basualdo Farjat JA 1993. Toxocariasis humana. Rev Arg Infect 6: 9-13.

Sanchez T, Pradenas G, Torres M, Canales M 1994. Sindrome de larva migrante visceral.Toxocariasis: enfermedad transmitida por perros. Rev Chile Infect 11: $17-22$.

Sellal F, Picard F, Mutschler V, Marescaux C, Collard M, Magnaval JF 1992. Myelite due a Toxocara canis (larva migrans). Rev Neurol 148: 53-55.

Sharkey J, Mc Kay PS 1993. Ocular toxocariasis in a patient with repeatedly negative ELISA titre to Toxocara canis. British J Oftalmol 77: 253-254.

Stenfancikova A, Havasiova K, Dubinsky P 1993. Serodiagnostika laválnej toxokarózy na Slovensku. Bratisl Lek Listy 94 c 2 s: 99-102.

Venturini LM, Radman NE 1988. Frecuencia de presentacion de $T$. canis, A. caninum y Giardia sp. según sexo y edad en caninos de La Plata (Buenos Aires -Argentina). Rev de Med Vet 69: 161-165.

Villano M, Cerillo N, Narciso L, Vizioli L, Del Basso de Caro M 1992. A rare case of Toxocara canis arachnoidea. J Neurosurg Sci 36: 67-69.

Woodruff AW 1975. Toxocara canis and other nematodes transmitted from dogs to man. Br Vet J 131: 627-632. 